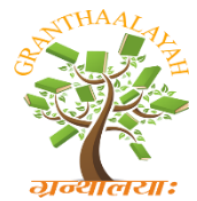

\author{
INTERNATIONAL JOURNAL OF RE
GRANTHAALAYAH \\ A knowledge Repository
}

Science

\title{
EFFECTS ON MODIFIED PROPERTIES OF EXPANSIVE CLAY SOIL USING WASTE HOLLOW CONCRETE BLOCK (HCB) AND CEMENT PLASTER WASTE MATERIALS FOR SUBGRADE CONSTRUCTION
}

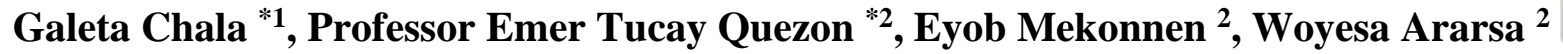 \\ ${ }^{1}$ Faculty of Civil Engineering, Ambo Institute of Technology, Ambo University, Ambo, Ethiopia \\ 2 Faculty of Construction Technology and Management, Ambo Institute of Technology, Ambo \\ University, P.O Box. 019, Ambo, Oromia Region, Ethiopia
}

\begin{abstract}
Expansive soils characterized by changing its volume and strength due to seasonal variations. Due to this volume changes, expansive clay soil caused many problems in road construction and is relatively common in Ethiopia. As a result, such types of soil are not adequately for road construction, which requires proper attention. The focus of this study was to improve the engineering properties of the expansive clay soil with the addition of waste materials to use as a subgrade construction material. Soil samples were taken from three locations within the study area and performed laboratory tests for the moisture content, specific gravity, free swelling, Atterberg limit, and compaction test on its natural state. The expansiveness of the soil from the three locations were determined. The highest value of expansiveness from these samples considered for the experiment by the addition of waste materials concentration with $5 \%, 10 \% 20 \%$, and $30 \%$ by weight. Test results indicated that the moisture content, free swelling, specific gravity Atterberg limit decreased, while the maximum dry density increased as the concentration of waste material increase. Hence, the minimum amount of waste materials comprised of $10 \%$ that will improve the strength of expansive clay soil for use in road subgrade construction.
\end{abstract}

Keywords: Expansiveness of Clay Soil; Cement Plaster Waste; Soil Properties; Waste Hollow Concrete Block.

Cite This Article: Galeta Chala, Professor Emer Tucay Quezon, Eyob Mekonnen, and Woyesa Ararsa. (2020). "EFFECTS ON MODIFIED PROPERTIES OF EXPANSIVE CLAY SOIL USING WASTE HOLLOW CONCRETE BLOCK (HCB) AND CEMENT PLASTER WASTE MATERIALS FOR SUBGRADE CONSTRUCTION." International Journal of Research - Granthaalayah, 8(3), 342-347. https://doi.org/10.29121/granthaalayah.v8.i3.2020.168.

\section{Introduction}

Expansive soils have many problems that pose several challenges for civil engineers. They are considered a potential natural hazard, which can cause extensive damage to structures if not 
adequately treated [1]. Expansive soils form a major soil group in Ethiopia and occur in the high lands, mostly in the western, central, and southwestern parts of the country. In most cases, the dominant clay mineral component is montmorillonite. The road sector in Ethiopia is suffering from the high shrink-swell behavior of this expansive soil. Many damages occur each year, and road construction over such expansive soil creates severe problems. It has a significant influence on planning, structural design, construction, maintenance costs, performance, and engineering life, especially for shallow foundation structures $[2,3]$. In Ethiopia, there are several roads, whose premature failures attributed to the volumetric changes of expansive clay soil; Modjo-Ejerie-Areti Road and Addis-Jimma Road could be examples of such failures [4]. In some instances on existing ravel and earth roads in Ethiopia, due to lack of budget, the concerned agency tried a mechanism to which the sub-base of the pavement to improve the soil properties to resist excessive deformation of the surface due to moving traffic loads. It is done through mechanical stabilization methods, sometimes neglecting the subgrade materials [5].

Improvement of expansive soil by different additives could be one solution to reduce the problem. However, most of the conventional stabilizing agents are relatively expensive to be implemented. Most stabilization is made by using lime, fly ash, sand, and cement. That was trying to stabilize in many countries since their occurrence is not specific by climate and problematic to engineering structures because they tended to heave swelling during the wet season and shrink during the dry season. Although the extent and range of distribution of this problematic soil have not been studied thoroughly, expansive soil is known to be widely spread in Ethiopia [6, 7].

Hence, it becomes essential to modify the properties of locally available soil to the extent that it can be used in the construction of roads and to make the best utilization of various waste material of construction like brick, HCB (Hollow concrete block) and cement plastering waste as a soil modifying stabilizing agent. Since the disposal of wastage from building construction sites require cost for the transporting and also require cost for a place where it would be disposed, especially in the urban area, it is foreseen that such wastages from hollow concrete blocks and cement plastering waste could be possible to use as stabilize for expansive soils where road projects can be constructed. The study focused on investigating the engineering properties of expansive soil by the addition and mixing wastage materials, and on determining the minimum amount to obtain the strength of the subgrade materials for road construction.

\section{Study Area, Materials, and Research Methods}

\subsection{Study Area}

The research study conducted at the Oromia region, west Shewa zone Ambo town. Ambo town is the capital town of West Shewa zone, with the land area of the town is 8,587.58 hectares and the population size of more than 114,333, including the population of expansion areas (Ambo municipality office, 2016). The geographical location of Ambo town is approximately between $8^{0} 56$ ' $30^{\prime \prime} \mathrm{N}-8^{0} 59^{\prime} 30^{\prime \prime} \mathrm{N}$ Latitude and between $37^{\circ} 47^{\prime} 30^{\prime \prime} \mathrm{E}-37^{0} 55^{\prime} 15^{\prime \prime}$ E Longitude. Relatively Ambo town is located $114 \mathrm{~km}$ far away west of Addis Ababa City. It is known that almost $90 \%$ of the land area in Ambo Town composed of expansive soils. 


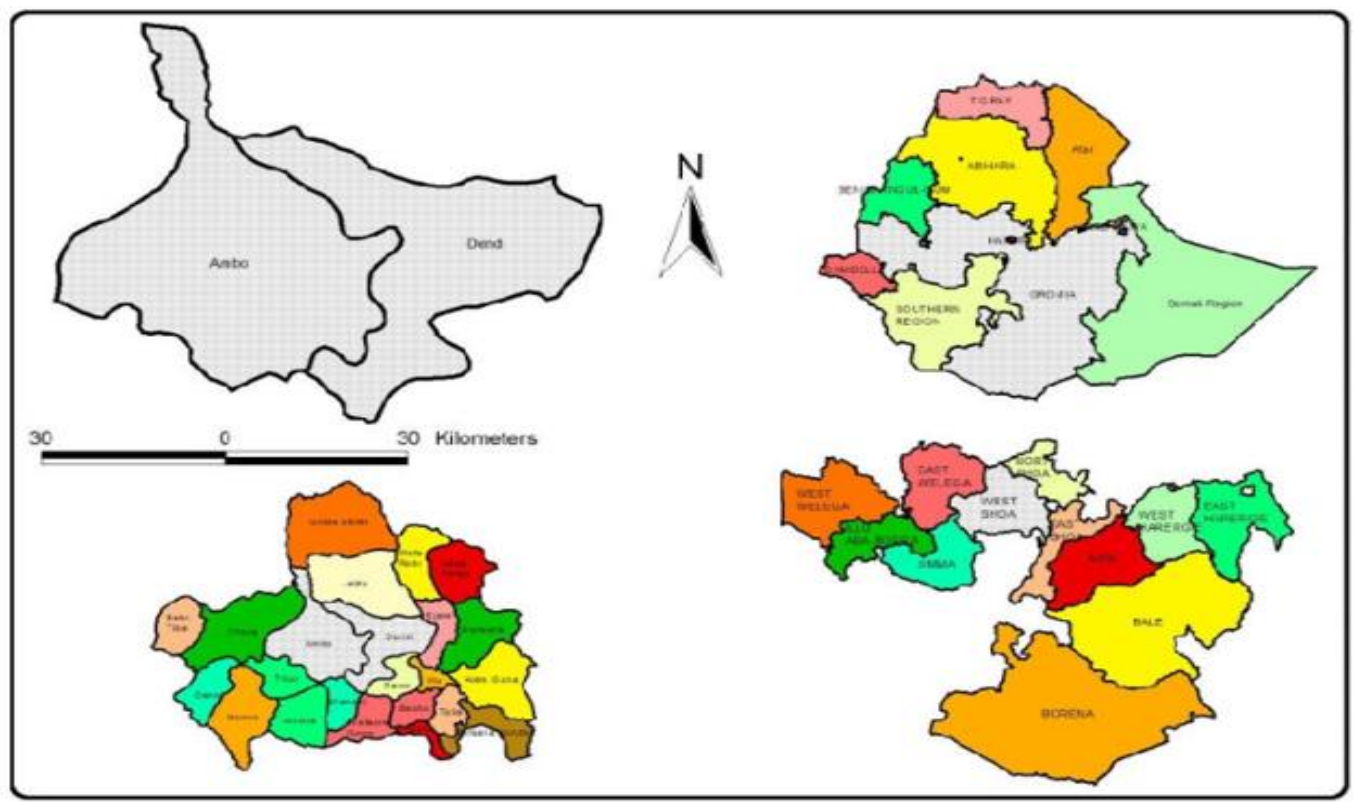

Figure 1.1: Map of the area (Source: Google map 2020)

\subsection{Materials}

\subsubsection{Sample Methods and Sampling Techniques}

The Samples collected randomly within the study area [8]. Three samples were taken at different locations: Sample-1 was taken around Awaro Qora kebele, which is around 1-km from Ambo Institute of Technology, Awaro campus. While sample-2 was taken in front of Awaro campus around the new football stadium, and sample-3 was extracted in front of Awaro campus main get near the Addis Ababa -Ambo highway. On the other hand, the waste materials collected from three different places in order to reduce the homogeneity of waste materials. Laboratory tests are conducted on soil samples before and after mixing with the waste materials.

\subsubsection{Testing Methods}

The laboratory tests conducted before stabilization of the natural soil samples include Moisture content, Specific gravity, Free swelling, Atterberg limits (liquid limit, plastic limit, plastic index), and compaction test. After the first phase of the laboratory tests, the same samples were used to mix with the waste hollow concrete blocks and cement plastering waste. The same procedures followed to determine the values of the parameters considered from the first phase. It was established by the addition of wastage materials consisting of 5\%,10\%, 20\% and 30\% by weight. All test procedures are based on ASTM and AASHTO $[9,10]$.

\section{Results and Discussion}

Initially, tests were conducted for the expansive soil on its natural state to determine the values of the different parameters; then, it was followed the second phase by the addition of waste material by increasing the concentration of waste materials concentration gradually. The three samples from 
the study area were tested to identify which sample would show the most expansiveness of the soil, and considered for the laboratory experiment. Sample-2 exhibited the highest value of the expansiveness of the clay soil. The laboratory test results for "with" and "without" waste material concentration is shown below.

\subsection{Moisture Content}

Table 3.1: Variation of moisture content "with" and "without" waste material concentration

\begin{tabular}{|l|c|}
\hline Sample specimen (Sample-2) & Moisture content \\
\hline Black cotton soil (BCS) & $26.2 \%$ \\
\hline BCS+5\% of WMC (Waste material concentration) & $25.8 \%$ \\
\hline BCS+10\% of WCM & $22 \%$ \\
\hline BCS+20\% of WCM & $20 \%$ \\
\hline BCS $+30 \%$ of WCM & $15 \%$ \\
\hline
\end{tabular}

In table 3.1, the test results indicated that the moisture content of expansive soil on its natural state was $26.30 \%$, but when the wastage materials added in the expansive soil with an incremental of $5 \%, 10 \%, 20 \%$ and $30 \%$ of the samples, the moisture content showed a significant decrease. These results show that the concentration of waste material added to the expansive soil, there was an indication of improved shearing strength and bearing capacity of the treated soil.

\subsection{Atterberg Limit}

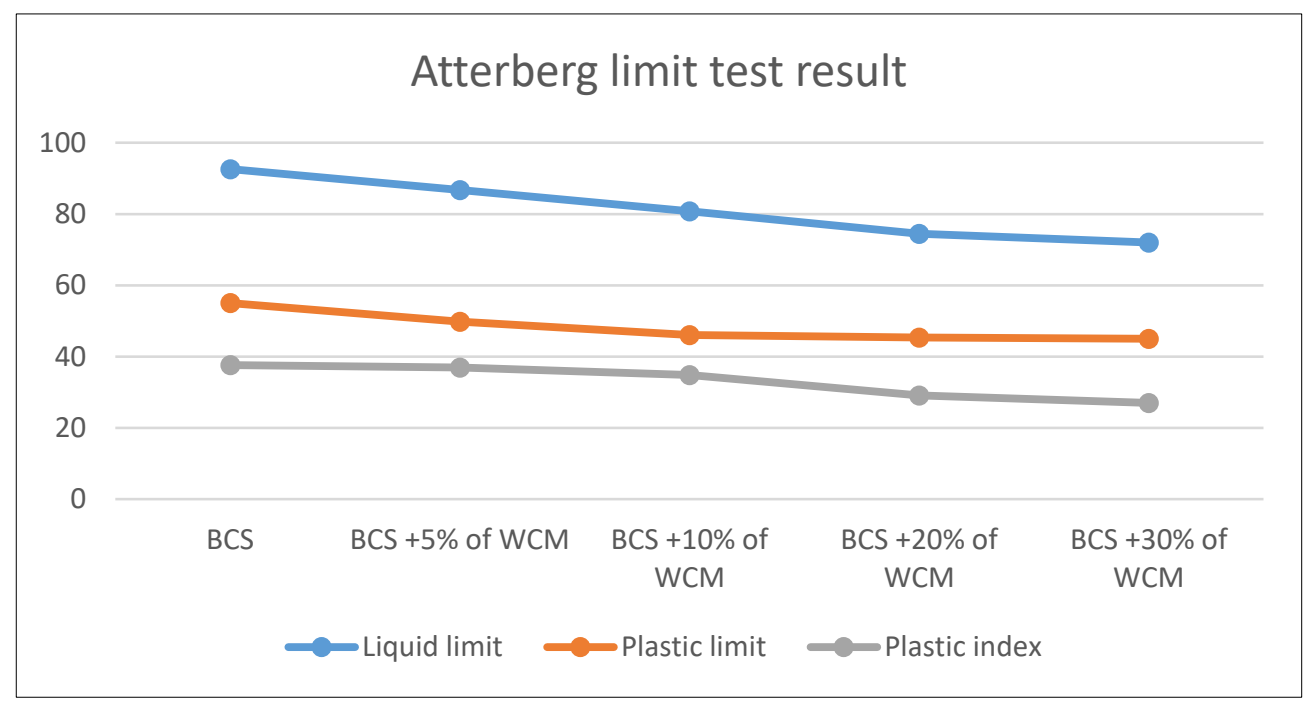

Figure 3.1: Variation of Atterberg limit test result with waste material concentration

As shown in figure 3.1, the value of liquid limits are continuously decreasing from $92.6 \%$ to $72 \%$ and $55 \%$ to $45 \%$ in the mixed specimen. While the plasticity index also decreased from $37.6 \%$ to $27 \%$. Hence, it was observed that the soil samples are inorganic soil of medium plasticity clay, and the waste materials( hollow concrete blocks and cement plaster waste) are inorganic fine of low plasticity. When the amount of the waste materials increases, the behavior of soil indicated from medium plasticity to low plasticity clay. 


\subsection{Proctor (Maximum Dry Density - Moisture content) test}

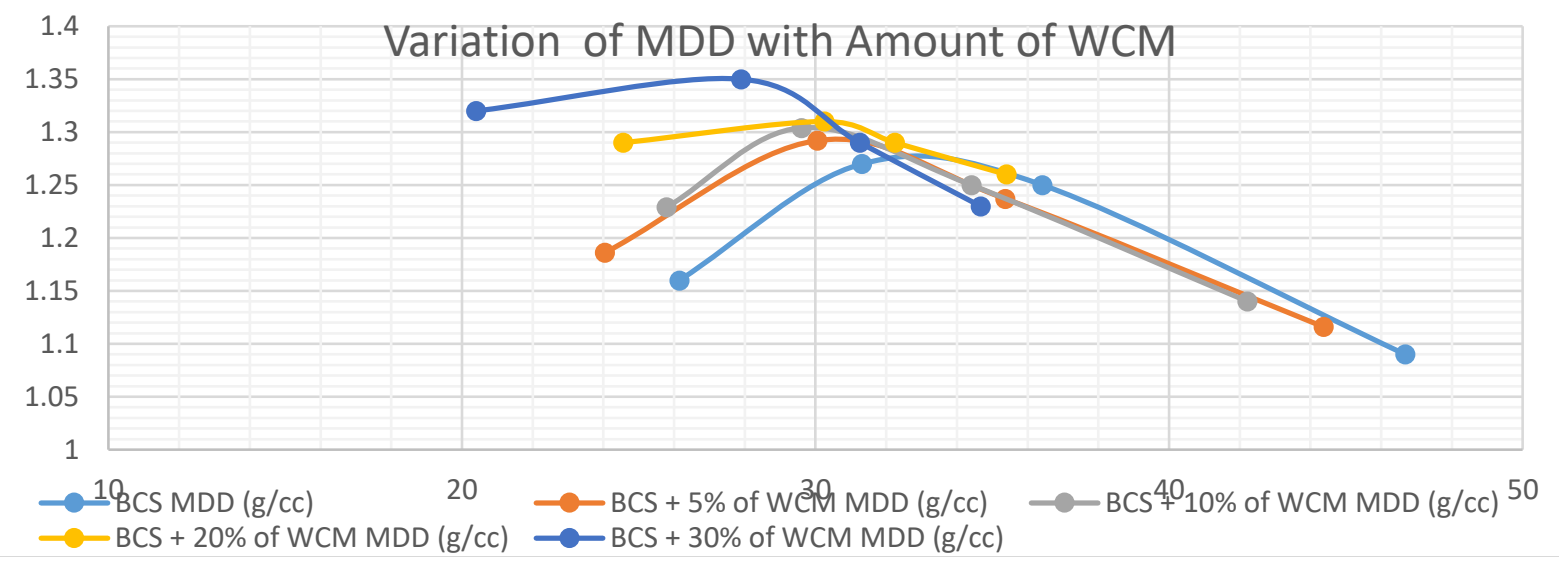

Figure 3.2: Variation of MDD with waste material concentration

The above figure showed the laboratory tests result of the maximum dry density (MDD) of expansive soil "with" and "without" the addition of the waste concentration material from construction. From these results, relatively, the maximum dray density at the lower optimum moisture content $(\mathrm{OMC})$ can be obtained.

\subsection{Free Swell Test Result}

Table 3. 2: Free Swell Index of Soil Sample with waste material concentration

\begin{tabular}{|l|l|}
\hline Soil sample and admixture & Free swell index (\%) \\
\hline 1.BCS only & 37.25 \\
\hline 2. BCS $+5 \%$ of WCM & 35.12 \\
\hline $3 . \mathrm{BCS}+10 \%$ of WCM & 33.44 \\
\hline $4 . \mathrm{BCS}+20 \%$ of WCM & 29.30 \\
\hline $5 . \mathrm{BCS}+30 \%$ of WCM & 25.05 \\
\hline
\end{tabular}

The free swell index showed a significant decreased, as the concentration of waste construction materials increased. This will prove that the waste material from construction used in this study can control the expansiveness of the clay soil as it improves the soil strength.

\section{Conclusion}

Based on the results of the research study, the following conclusions are drawn:

- The engineering property of the studied expansive clay soil showed not suitable to use as a sub-grade unless its undesirable properties are rectified.

- From the test results, the liquid limit and plastic limit implied a reduction in its value when it was added percentages of waste construction materials. This shows that the black cotton soil changes from the clay of high compressibility nature to the clay of low compressibility. Thus, waste material from the construction, as in the case of this study, are found to have influence on the index and physical properties of black cotton soil to make the soil suitable for road construction as a subgrade foundation material for a road project. 
- On treatment with waste material from construction, the plastic nature of soil had decreased, which in turn a contributory to gain in strength of the clay soil.

- Expansive clay soil treated with waste material of constructions by 5\%,10\%, 20\%, and $30 \%$ by dry weight of the soil showed significant improvement in strength. It satisfactorily minimized swelling property of the native soil.

Generally, it is observed that with the increasing material wastage in building constructions, the usage of these materials as an additive for expansive clay soils would help the town to properly dispose of such kind of waste materials by not adversely affecting the environment.

\section{References}

[1] Arunav Chakraborty and Swapnaneel Roy: "Study on the properties of expansive clayey soil using Coconut Husk Ash (CHA) as stabilizer;" ADBU-Journal of Engineering Technology; AJET, ISSN: 2348-7305; Vol 4(1), 94-97 (2016).

[2] McKeen, R.G, 1976, Design and Construction of Airport Pavements on Expansive Soils; U.S Department of Transportation, Federal Aviation Administration, Systems Research and Development Service, Washington, D.C. 20590

[3] Robel Tewelde Mesfun, Emer Tucay Quezon, and Anteneh Geremew. "Experimental Study of Stabilized Expansive Soil Using Pumice Mixed with Lime for Subgrade Road Construction.” International Journal of Research - Granthaalayah, 7(7), 118-124. (2019). https://doi.org/10.5281/zenodo.3355594.

[4] Taye, T.: "Stabilization of Expansive Clay Soil with Sugar Cane Molasess and Cement." MSc Thesis; Road and Transport Engineering, AAU, Addis Ababa City (2015).

[5] Edire Erko Esho, Emer Tucay Quezon, and Democracy Dilla. "Effects of Mechanically Stabilized Graded Assorted Coarse-Grained Soils in the Performance of Unpaved Road: A Case Study In Goffa Zone, Sawla Area.” International Journal of Research - Granthaalayah, 7(8), 133-156. (2019). https://doi.org/10.5281/zenodo.3380234.

[6] ERA (2013). Ethiopian Roads Authority. Site Investigation Manual. Addis Ababa, Ethiopia

[7] J. Olufowobi. "Clay Soil Stabilisation Using Powdered Glass;" Journal of Engineering Science and Technology; Vol. 9, No. 5 (2014) 541 - 558 (2014)

[8] ERA (2002). Ethiopian Roads Authority. "Site Investigation Manual." Addis Ababa, Ethiopia.

[9] ASTM (2003). "American Society for Testing and Materials." Annual of Book of ASTM Standards. Volume 04.08. Soil and Rock (I): D 420-D-5611.100 Barr Harbor Drive. West Conshohocken, PA 19428-2959

[10] AASHTO (2008). American Association of State Highways and Transport Officials. "Standard Recommended Practice for Stabilization of Sub-grade Soils and Base Materials". Washington, D.C.20001

[11] Chen, F.H., 1988, "Foundations on expansive soils," Chen and Associates, 96 South Zuni, Denver, CO80223, U.S.A.

[12] Gautrans (March 2004). Manual L 2/04, "Stabilization Manual." Department of Public transport, Gauteng Provincial Government, Pretoria.

[13] Yibas Mamuye, Emer Tucay Quezon and Anteneh Geremew. "Combined Effects of MolassesLime Treatment on Poor Quality Natural Gravel Materials Used for Sub-Base and Base Course Construction;" GSJ: Volume 6, Issue 7; ISSN 2320-9186; 621-633 (2018).

* Corresponding author.

E-mail address: galetachala@gmail.com/quezonet09@gmail.com 